\title{
Potências cerebrais através do estímulo acústico (AEP) mostram a audição no peixe-boi (Sirenia: Trichechus inunguis) (1)
}

\author{
Theodore H. Bullock $\left({ }^{2}\right)$ \\ Daryl P. Domning $\left({ }^{3}\right)$ \\ Robin C. Best $\left({ }^{4}\right)$
}

\begin{abstract}
Resumo
Um jovem peixe-boi da Amazônia (Trichechus inun. guis) mostrou boas respostas auditivas evocadas, com a máxima sensibilidade em cerca de $3 \mathrm{kHz}$ e alcançando de $200 \mathrm{~Hz}$ a $35 \mathrm{kHz}$, mas não a $40 \mathrm{kHz}$. A sensibilidade máxima foi encontrada a cerca de $20 \mathrm{~mm}$ rostralmente ao canal auditivo externo, possivelmente implicando a larga parte posterior do processo zigomático do osso squamosal, no sistema acústico desta espécie. As técnicas utilizadas nesta pesquisa são recomendadas para estudos futuros de sensibilidade acústica de animais para sons simples ou sons complexos que tem começos relativamente bruscos.
\end{abstract}

\section{INTRODUÇÃO}

É bem conhecido o fato de que os sirênios produzem vocalização em baixo d'água. Alguns destes sons foram registrados e analisados em duas espécies de peixe-boi, Trichechus manatus (Schevill \& Watkins, 1965; Sonoda \& Takemura, 1973), T. inunguis (Evans \& Herald, 1970); e, sons produzidos por Dugong dugon foram registrados no ar (Nair \& Lal Mohan, 1977). Fleischer (1971) analisou a freqüência oscilatória dos ossículos do ouvido do dugongo em preparações com esqueletos secos (os resultados obtidos através desta técnica devem, contudo, ser vistos com muito cuidado). Observações feitas em peixe-boi selvagem (por exemplo, Hartman, 1971), sugerem que o ouvido destes animais é sensivel (de acordo com a crença dos pescadores; Veríssimo, 1895) e mostra que eles produzem sons audiveis quando sozi- nhos e quando interagindo socialmente; vacas e bezerros em particular usam vocalização provavelmente para manter contato. Em sirênios cativos foram observados respostas a sons produzidos pelo homem (por exemplo, Vosseler, 1975; Bertram \& Bertram, 1964, e observações pessoais Domning \& Best).

A presença de um centro acústico razoavelmente normal no cerébro do mamífero (Verhaart, 1972) sugere que o peixe-boi ouve bem, enquanto centros menores da visão indicam que este sentido é menos importante. Estas observações estão de acordo com as idéias de Marsh et al. (1978), no que diz respeito à sensibilidade auditiva do dugongo. No entanto, nenhum estudo fisiológico foi conduzido no sentido da audição dos sirênios.

Este trabalho surgiu de uma oportunidade incomum apresentada pelo acesso a um peixeboi do Instituto Nacional de Pesquisas da Amazônia (INPA), Manaus, Brasil, enquanto uma unidade de registros eletrofisiológicos do cérebro estava dísponivel. Na ausência de um geradior e de um recinto apropriados para o estímulo acústico, ncsso objetivo foi apenas um experimento qualitativo e preliminar. Esta demonstração de que um simples método fisiológico, sem necessidade de condicionamento do animal, basta para manifestar respostas do cérebro e sons arbitrários no peixe-boi abre o caminho para um estudo mais profundo.

(1) - Versão original inglesa publicada em- J. Mammal. 61(1): 130-133, 1980.

(2) - Neurobiology Unit, Scripps Institution of Oceanography and Department of Neurosciences, School of Medicine, University of California, San Diego A-001, La Jolla, California 92093.

(3) - Department of Anatomy, College of Medicine, Howard University, Washington, D.C. 20059.

(4) - Instituto Nacional de Pesquisas da Amazônia, Manaus, e Vancouver Public Aquarium, Vancouver, British Columbia, Canadá. 


\section{MATERIAL E MÉtodos}

Um jevem macho (menos de 1 ano) $T$. inunguis pesando em torno de $20 \mathrm{~kg}$, foi estudado, registrando-se seus potenciais evocados transcranianos sobre o cérebro. Este animal ficou cativo por aproximadamente nove meses, es. tava em bom estado de saúde e apresentava reações aparentemente normais a vários estímulos, produzindo "guinchos" fracos. Sobre este aspeco ele parecia a muitos animais em idade pré-adulta mantidos em grupos sociais; registramos suas vocalizações, mas as reações atribuídas à audição não foram muito consistentes.

Em quatro sessões de aproximadamente duas horas cada, durante o período de duas semanas, registramos o potencial evocado do peixe-boi amarrado a uma maca, no ar, dentro de uma sala espaçosa com sons ambientais altos e variáveis. Pequenos estalidos e sons em rajada com rampa de entrada e de saída de 10-50 mili-segundos (ms), com um platô de $10-100 \mathrm{~ms}$ foram emitidos a cada 0.3 a 2.5 segundos de um alto-falante, ou de um grande par de fones de ouvido, mantidos sobre a área sensivel do animal (ver abaixo), ou uns pequenos fones de ouvido colocados sobre a pele em vários lugares. Eletrodos foram as agulhas hipodérmicas, inseridas intradermicamente ou finos fios foram inseridos dentro dos buracos feitos por tais agulhas; cuja colocação é descrita mais adiante. O eletrodo de referência foi colocado na linha média da região parietal. Os potenciais registrados bipolarmente foram ampliados e filtrados (linear entre 3 a $300 \mathrm{~Hz}$ ). O exame das respostas usando um filtro acústico com limite superior de $1 \mathrm{kHz}$ não mostrou mudanças nas suas formas. Os artefatos de movimentos musculares não foram um problema sério, com exceção de alguns movimentos nítidos que ocorriam em investidas após intervalos úteis de calma. A batida do coraçãc, em nossos eletrodos, mostraram um pequeno EKG. Os potenciais correlacionados com tempo e estímulo acústico foram registrados e suas médias calculadas, usando-se um computador (Modelo Nicolete 1150, digital) e colocados num gráfico $x-y$. Para explorar a cabeça quanto à sensibilidade local, um pequeno alto-falante, (um "plug" de orelha de $10 \mathrm{~mm}$ de diâmetro) foi pendurado a uns poucos milímetros da pele e ao longo dela movimentado.

Dois eletrodos ativos foram usados, ambos na linha média, sendo que um deles na linha transversal a meio caminho entre o olho e o canal acústico externo e outro $3 \mathrm{~cm}$ atrás conseqüentemente próximos da parte anterior e mediana do cerébro, respectivamente). Os principais picos dos potenciais evocados médios (AEP) tanto para pequenos estálidos como para sons com rajadas, mostraram deflecções positivas e depois negativas, as primeiras alcançando seu máximo em cerca de $80-95 \mathrm{~ms}$ e as negativas em cerca de 110-150 ms (Fig. 1). Não pesquisamos a melhor colocação dos eletrodos e o arranjo dos eletrodos bipolares significa que a polaridade das deflecções é arbitrária. A latência foi completamente lábil com as taxas de repetição. Algumas vezes era mais curta, com estalidos mais freqüentes (por exemplo 3,7 por segundos) que como menor freqüência (de 1,4 por segundo), mesmo que este último causasse deflecçōes maiores. Um total de 16 a 32 respostas normalmente bastava para salientar estes AEP. Contudo, não só a latência, mas a amplitude do A.EP era lábil, al-

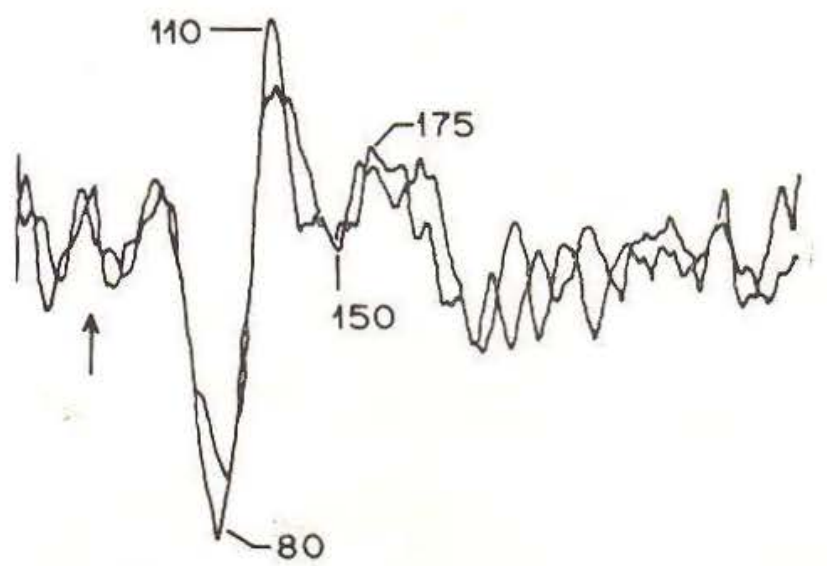

Fig. 1 - Potenciais evocados médios de dois fios finos colocados intradermicamente na linha média sobre os ossos parietais e frontais, em resposta a um som em rajada cada 1,6 segundos de $3 \mathrm{kHz}$, com uma rampa de entrada e de saída de $3 \mathrm{~ms}$ e um platô de $5 \mathrm{~ms}$ fornecido por um "plug" de ouvido mantido perto do canal auditivo externo esquerdo, no momento indicado pela seta. Duas somatórias de 64 respostas cada é aqui apresentada; os números são mili segundo de início do som. 
gumas vezes inexpilcavelmente pequena ou subitamente muito maior; talvez devido a algumas mudanças no estado do animal e em córtex.

\section{RESULTADOS OBTIDOS}

A freqüência que deu a maior resposta sob nossas condições foi em cerca de $3 \mathrm{kHz}$, mas o máximo não foi bem definida. Não pudemos enviar sons em rajadas, comprecisamente o mesmo conteúdo de energia numa larga faixa de freqüências. No entanto, houve poucas mudanças sistemáticas de energia, pelo menos entre cerca de 300 e $6000 \mathrm{~Hz}$, registradas por um bom microfone. Os AEP foram observados de $200 \mathrm{~Hz}$ até a $35 \mathrm{kHz}$, mas nunca a $40 \mathrm{KHz}$; isto é provavelmente porque o menor estímulo efetivo foi mascarado por barulhos ambientais e que os fones de ouvido estavam atenuando muito as freqüências mais altas usadas.

A recuperação a uma segunda resposta de estálido ou sons em rajadas breves é lento por exemplo, testando depois de vários intervalos o AEP com um segundo estálido, $200 \mathrm{~ms}$ depois do primeiro, ambos foram pequenos e bastantes diferentes na forma. A recuperação completa levou mais de $1,4 \mathrm{~s}$. Simultaneamente o ruido branco (que se apresenta em todas as freqüências de onda) mascarava os estálidos e os sons em rajadas, isto é: os AEP foram deprimidos ou suprimidos.

A exploração da cabeça com um peçueno alto-falanie mostrou que a região mais sensivel se localiza aproximadamente $20 \mathrm{~mm}$ da área rostral ao canal acústico externo. Esta região fica diretamente sobre a parte mais larga e posterior do processo zigomático, do osso esquamosal.

$\mathrm{Na}$ configuração usada dos eletrodos, a luz não pareceu causar nenhum potencial evocado significativo; isto pode ser devido à posiçâo desfavorável dos eletrodos, bem como à visão pouco desenvolvida dos animais. A emissão de uma luz estroboscópica deu um AEP que entretanto continuou e foi apenas maior quando a lâmpada foi coberta. Provavelmente o está- lido audivel associado a cada lampejo foi 0 estímulo, pois o ruído branco suprimiu o AEP.

C tamanho do potencial medido (Fig. 1) não pode ser comparado, diretamente com o dos mamíferos conhecidos, não se pode dizer, através dessa nossa evidência limitada, que este seja grande ou pequeno. Não só o crânio é espesso e a colocação de eletrodos única (próximos na linha mediana, bipolares) provavelmente subótimos, pois que o cerébro é de uma forma bizarra (Verhaart, 1972); tal que nenhum dos fatores que influenciam a amplitude puderam ser avaliados como até agora. Além disso, AEP variou amplamente de tempos em tempos.

\section{DISCUSSÃo}

O pico de sensibilidade que registramos (cerca de $3 \mathrm{kHz}$ ) concorda aproximadamente com as taxas de freqüência das vocalizações observadas em T. inunguis $16-8 \mathrm{kHz}$, Evans \& Herald, 1970; $2-3$ e raramente a $10 \mathrm{kHz}$, Sonoda \& Takemura, 1973); T. manatus $(2,5-5 \mathrm{kHz}$, Schevill \& Watkins, $1965 ; 2-7 \mathrm{kHz}$, Sonoda \& Takemura, 1973), e Dugong (3-8 kHz, Nair \& Lal Mohan, 1977). Apesar do uso de ossículos secos, dos quais deveria ser esperado um resultado confuso, Fleischer (1971) observou surpreendentemente uma faixa de ressonância similar $(2-4 \mathrm{kHz})$ para a cadeia ossicular de Dugong.

É de particular interesse o fato de que a sensibilidade máxima para sons localizados é encontrada por sobre uma área apenas rostral ao canal auditivo em vez de sobre o canal propriamente dito. É claro que isto pode ser influenciado pelo fato do canal acústico externo conter ar, água ou cera além do seu normal e peio menos ser parcia!mente obstruído por tecidos. Não tentanios controlar ou averiguar esta ocorrência. A área mais rostral é o local do largo processo zigomático do osso esquamosal. Em Trichechus este processo é acentuadamente expandido e composto de ossos esponjosos saturados de óleo. Ainda não foi propostã nenhuma função para estas estruturas 
pecuilares. Em vistas das presentes descobertas e do papel das cavidades preenchidas por lipídios em mandibulas de cetáceos odontocetos (Norris, 1968; Bullock et al., 1968), a pos sibilidade de que isto esteja relacionado com a condução do som deveria ser investigada. Estudos relativos às propriedades acústicas de lipídios encontrados em cavidades de ossos deveriam elucidar melhor este aspecto. Entretanto deve ser lembrado que o canal mandibu. lar de odontocetos funciona como um guia de ondas e que é muito diferente na forma estrutural dos canais do processo zigomático do peixe-boi; e se este último serve como condutor de som, seu papel deve ser completamento diferente.

O método de estudo da audição através do registro de AEP transcranialmente é agora rotina na audiologia humana, mas tem sido muito pouco explorada através de um levantamento da sensibilidade acústica em outras espécies. Mais comumente os eletrodos foram colocados ou introduzidos dentro do cérebro, depois perfurados os crânios e registrados, com a vantagem de um sinal de amplitude maior e com menos artefatos. Mesmo este método não tem sido tão amplamente usado como deveria.

Tentamos ver AEP acústicos precoces ( $<10 \mathrm{~ms}$ ) atribuídos aos primeiros e poucas escalas no carninho auditivo, no tronco cerebral, agora muio bem estudados nos seres humanos, realizando médias de milhares em vez de dezenas de respostas. Sob nossas condi. ções, os artefatos cresceram nestas longas médias e falhamos em perceber as deflecções confiáveis no tronco cerebral. Mesmo se este probiema fosse resolvido, os últimos picos, presumivelmente dos hemisférios cerebrais, deveriam ser utilizados pelos zoólogos, tanto para sons simples como para sons complexos, que têm começo relativamente brusco. Quando as condições são favoráveis, o poder do método pode ser bastante alto, não só representando a sensibilidade como uma função de freqüência, como também no estudo de mascaramento por outros sons, dinâmica de recuperação, facilitação e outras, as vezes sutis diferenças no valor de implantação de sons complexos com significados etológicos diferentes.

\section{AGRADECIMENTOS}

Este trabalho foi realizado no Instituto $\mathrm{Na}$ cional de Pesquisas da Arnazônia (INPA), Amazonas, Brasil, como parte de um programa de pesquisas em andamento sobre a biologia do peixe-boi da Amazônia. Este programa é mantido pelo Conselho Nacional de Desenvolvimento Científico e Tecnológico (CNPq) do Brasi! e apoiado por Vancouever Public Aquarium, British Columbia, Canadá e a Fauna Preservation Society of Great Britain. T. H. Bullock foi auxiliado por subvenção da U.S. National Insthtute of Neurological Science Foundation and Communicative Disorders and Stroke and the National Science Foundation. Agradecemos ao Dr. F. Pimentel de Souza pela ajuda na tradução.

\section{SUMMARY}

A young Amazonian manatee (Trichechus inunguis) showed peak auditory sensitivity at about $3 \mathrm{kHz}$ and averaged evoked potentials (AEP) from $200 \mathrm{~Hz}$ to $35 \mathrm{kHz}$ but not at $40 \mathrm{kHz}$ as measured by transcranial evoked potentials. The maximum sensitivity was recorded about $20 \mathrm{~mm}$ rostral to the auditory meatus, possibly implicating the broad posterior part of the zygomatic process of the squamosal bone in the acoustic system of the manatee. The techniques used in this study are recommended for studies of acoustic sensitivity of animals to simple and complex natural sounds that have relatively abrupt onsets.

\section{REFERENCIAS BIBLIOGRÁFICAS}

BERTRAM, G.C.L. \& BERTRAM, C.K. Ricardo

1964 - Manatees in the Guianas. Zoologica, 49 (2): 115-120.

BULLOCK, T.H.; GRINNELL, A.D.; IKEZONO, E.; KAMEDA. K.; KATSUKI, Y.; NOMOTO, N.; SATO, O.; SUGA, N.; YANAGISAWA, $K$.

1968 - Electrophysiological studies of central suditory mechanism in cetaceans. Zs. vergl. Physiol., 59: 117-156.

EVANS, W.E. \& HERALD, E.S.

1970 - Underwater calls of a captive Amazon manatee, Trichechus inunguis. J. Mamm., 51: 820-823.

FLEISCHER, G.

1971 - Ueber Schwingungsmessungen am Skelett des Mittelohres von Halicore (Sirenia), Zs. Säugetierk., 36: 350-360. 
HARTMAN, D.S.

1971 - Behavior and ecology of the Florida manatee, Trichechus manatus latirostris (HarIan), at Crystal River, Citrus Country, Ph.D. dissertation, Cornell Univ., Ithaca, N.Y. 285p.

MARSH, H.; SPAIN, A.V.; HEINSOHN, G.E.

1978 - Physiology of the dugong. Comp. Biochem. Physiol., 61A: 159-168.

NAIR, R.V. \& MOHAN, R.S. Lal

1977 - Studies on the vocalisation of the sea cow Dugong dugon in captivity, Indian J. Fish, 22 (1/2): 277-278.

NORRIS, $\mathrm{K}$.

1968 - The evolution of acoustic mechanisms in odontocete cetaceans, pp. 297-324, Drake, E.T. ed. Evolution and environment, New Haven, Yale Univ. Press, 470p.

SCHEVILL, W.E. \& WATKINS, W.A.

1965 - Underwater calls of Trichechus (manatee) Nature, 205: 373-379.
SONODA, S. \& TAKEMURA, A.

1973 - Underwater sounds of the manatees, Trichechus manatus manatus and $T$. inunguis (Trichechidae). Rep. Inst. Breeding Res., Tokyo, (4): 19-24.

VERHAART, W.J.C.

1972 - The brain of the seacow Trichechis (sic) Psych. Neurol. Neurochor, (75): 271-292.

VERISSIMO, J.

1895 - A pesca na Amazônia. Rio de Janeiro, Livr. Clássica de Alves \& C., 206p. (Reprinted 1970, Univ. Fed. do Pará, 130p.) .

VOSSELER, J.

1925 - Pflege und Haltung der Seekühe (Trichechus] nebst Beiträgen zu ihrer Biologie. Pallasia, 2: 213-230.

(Aceito para publicação em $14 / 10 / 80$ ) 